\title{
Desarrollo de la comunicación oral y escrita como competencia genérica en la formación profesional de estudiantes de Ingeniería Civil
}

\author{
Yesenia Aréniz-Arévaloa* \\ aMagister en Prácticas pedagógicas., Universidad Francisco de Paula Santander, Ocaña. \\ Forma de citar: Aréniz, Y. (2017). Desarrollo de La comunicación oral y escrita como competencia \\ genérica en la formación profesional de estudiantes de Ingeniería Civil. Perspectivas, 2(2). 60-72.
}

Recibido: octubre 02 de 2016

Aceptado: febrero 18 de 2017

\begin{abstract}
Palabras clave
Competencias genéricas, comunicación oral, comunicación escrita, alfabetización académica, educación superior
\end{abstract}

*Autor para correspondencia yareniza@ufpso.edu.co
Resumen: El mundo contemporáneo se caracteriza por los cambios vertiginosos generados a partir de la globalización, el impacto de las tecnologías de la información y la comunicación, la sociedad del conocimiento y la necesidad de gestionar la diversidad. En este entorno es necesaria un tipo de educación superior significativamente distinta que obligue a la Universidad a repensar sus tradicionales funciones y responsabilidades frente al tipo de profesional que se está formando. En este sentido, el propósito del estudio consistió en la evaluación del desarrollo de la comunicación oral y escrita como competencia genérica entre estudiantes de Ingeniería Civil en la Universidad Francisco de Paula Santander. Para ello se utilizó un diseño metodológico mixto, predominantemente cualitativo complementado por cuestionarios. El análisis estadístico permitió describir y evaluar un conjunto de categorías inductivas asociadas a la comunicación oral y escrita derivada de una categoría deductiva previamente teorizada. Se utilizaron como instrumentos cualitativos la pintura enriquecida y el análisis de escritos; para la obtención de los datos para el análisis cuantitativo se empleó un cuestionario con escalas tipo Likert que se respaldaron y complementaron con cálculos estadísticos provenientes de diversas plantillas de control. 


\section{Keywords}

Generic skills, oral communication, written communication, academic literacy, higher education

\section{Palavras chave}

Habilidades genéricas, comunicação oral, comunicação escrita, alfabetização
Los resultados establecen las categorías inductivas que explican el déficit mostrado por los estudiantes en la apropiación de esta competencia genérica, lo cual permite reflexionar acerca de la responsabilidad que tienen las instituciones educativas, incluso en el nivel superior, para la adquisición y desarrollo de competencias de lectura y escritura.

Development of oral and written communication as a generic competence in the professional training of Civil Engineering students

Abstract :The contemporary world can be characterized by the dramatic changes brought on by globalization, the impact of information and communication technologies, the knowledge society and the commitment to manage diversity effectively. In this context, a significantly different type of higher education is needed to force the University to reevaluate its traditional functions and responsibilities regarding the type of professional the university is educating. Accordingly, the investigation aimed to evaluate the development of oral and written communication as a generic competence among students of Civil Engineering at the University Francisco de Paula Santander. For this, a predominantly qualitative, mixed method study design was used, complemented by questionnaires. The statistical analysis allowed us to describe and evaluate a set of inductive categories associated with oral and written communication, derived from a previously theorized deductive category. The enriched painting and analysis of writings were used as qualitative instruments; for the collection of data conducive to the quantitative analysis, a questionnaire with Likert - type scales was used, supported and complemented with statistical calculations from various control templates. The results establish the inductive categories that explain the students' shortcomings as shown in the appropriation of this generic competence, which allows us to reflect about academic institution's responsibility, even in higher education, to help students acquire and develop reading and writing skills.

\section{Desenvolvimento da comunicação oral e escrita como uma competência genérica na formação profissional dos estudantes de engenharia civil}

Resumo: O mundo contemporâneo caracteriza-se pelas vertiginosas mudanças geradas pela globalização, o impacto das tecnologias da 
acadêmica, ensino

superior

\section{Introducción}

Puesto que desde muy niños hemos aprendido a hablar nos inclinamos a pensar que lo hacemos bien y que, al hacerlo, creemos que no tenemos problemas al comunicarnos con los demás (Villa y Poblete, 2007 ). Este supuesto queda en entredicho si hacemos un análisis, así sea superficial, en la vida cotidiana. Los equívocos en la comunicación están a la orden del día. Pensamos que decimos lo que queremos decir y el que está escuchando ha comprendido todo lo que le hemos expresado, pero la realidad nos muestra que tanto en nuestra existencia individual como en las interacciones en nuestras relaciones personales y profesionales, existen dificultades comunicativas de distinto grado.

La capacidad de comunicarnos y su dominio implica que el interlocutor entienda ideas, conocimientos y sentimientos a través de las palabras, y que en situaciones y escenarios diversos sea eficaz para trasladar una idea o un conocimiento (Fraca, 2003). Por otra parte, existen personas muy introvertidas, cuya participación activa es poco frecuente. Una de las posibles causas de este comportamiento puede hallarse en limitaciones psicológicas como la falta de confianza en uno mismo o el miedo de expresar ideas o emociones. Este tipo de personas, en efecto, tiene temor de ser señalados o rotulados. Sin embargo, los problemas más frecuentes están relacionados con la expresión confusa y poco ordenada que impide la comprensión por parte de las demás personas, la falta de una estructura lógica en la expresión, el desequilibrio entre lo que se piensa, se siente y como se actúa.

Dominar esta competencia genérica, en la otra cara de la moneda, supone claridad y eficacia en la comunicación, organización en orden y estructura del discurso, acomodarse a la audiencia, la combinación entre el lenguaje verbal y el corporal, 
el uso de una voz adecuada y, en general, la habilidad de transmitir realmente lo que se quiere comunicar (Ríos, 2008). Dominar esta competencia es saber intervenir en un escenario determinado uniendo el contenido del discurso y el carisma del orador persuadiendo al escuchar en su forma de pensar y de actuar teniendo repercusiones sociales muy considerables (Romero, 2005 ; Borrero, 2008).

La comunicación oral es definida por Villa y Poblete (2007) como toda expresión de ideas, conocimientos y sentimientos transmitida con claridad, ajustándola a las características de la situación de un escenario y audiencia para alcanzar su discernimiento y su asociación.

Para estos autores, el dominio de esta competencia está estrechamente relacionado con el pensamiento reflexivo, el pensamiento deliberativo, el pensamiento conjunto, la auto motivación, la comunicación interpersonal, el manejo de otros idiomas, el trabajo en equipo, negociación, liderazgo, autoestima, prestigio de la propia imagen y confianza (Villa y Poblete, 2007:186 ).

En este sentido, un simple documento, escrito o carta, comunica no solo contenidos sino también un retrato del autor. Si cualquier escrito es claro, gramaticalmente correcto y contiene explicaciones o se fundamenta en gráficos, genera en el lector una imagen atractiva, se lee con agrado y logra fundamentar una relación poderosa entre el autor y el lector. Si por el contario, no tiene estas características, se torna aburrido, invita a su renuncia y no cumple con su objetivo inicial, que es el de comunicar.

La capacidad de comunicar ideas, información y emociones a través de un escrito y con ayuda de gráficos no es innata. Se desarrolla con la experiencia, siguiendo un libreto o copiando patrones a lo que accedemos a través de la lectura. Esto permite seguir una estructura en un escrito cualquiera teniendo en cuenta el orden en la exposición y la claridad en el léxico, la estructura de las frases y el uso de la ortografía (Díaz, 1999). La utilización y apoyo de gráficos y tablas complementa el escrito y condensa lo que con las palabras podría serde alta dificultad y de una complejidad difícil de entender.
El objetivo de un escrito, por ejemplo, es esencial para permitir la lectura y la comprensión. La utilización de las palabras adecuadas, así como de conclusiones o recomendaciones finales que resuman de manera apropiada el texto central, favorecen la comprensión y el recuerdo del documento. La elección de las palabras adecuadas, sin caer en imprecisiones y equívocos, evitando en el texto repeticiones improductivas, así como la utilización de ejemplos o figuras que esclarezcan aspectos complejos, permiten a lector fluir en una lectura amena y entendible. Es tarea de la universidad contribuir con el desarrollo en el estudiante de la capacidad de construir textos correctos y apropiados (Morales, 2002 ; Zabalza, 2005).

Estas destrezas en la expresión tanto oral y escrita deberían formar parte de las competencias que un estudiante universitario trae ya consolidadas desde las etapas anteriores de su formación. Sin embargo, los estudiantes universitarios demuestran falencias al momento de expresarse, de redactar un escrito, de comunicar una idea. Estas afirmaciones se pueden comprobar fácilmente en los resultados de pruebas saber PRO en los apartados relacionados con la lectura crítica y comunicación escrita, que cada vez parecen ser más deficientes.

En este sentido, el presente estudio se propuso evaluar el desarrollo de la comunicación oral y escrita como competencia genérica entre estudiantes de Ingeniería Civil en la Universidad Francisco de Paula Santander. Se destaca así el carácter fundamental de esta competencia en la formación del nuevo profesional en la expresión de las ideas ante un equipo de trabajo, en general, para su comunicación con los demás, todo lo cual contribuirá en el futuro a su empleabilidad y posibilitar mejores oportunidades para su inserción al mercado laboral. Después de todo, la educación por competencias es el modelo que ha demostrado ser de gran utilidad incluso en la educación superior (Cano, 2008). Y un docente adecuadamente formado debe ser capaz de enfrentar los retos y desafíos con independencia del nivel educativo 
en el que se desempeñe (Camargo et al., 2004 ; Comellas, 2002 ; Galvis, 2007 ).

\section{Materiales y métodos}

El estudio se considera de naturaleza mixta, pues a pesar de predominar el enfoque cuantitativo se complementa con métodos cuantitativos tales como la aplicación de cuestionarios y análisis estadísticos descriptivos. Esta combinación de metodologías permite aproximarse con mayor rigor al objeto de estudio: el desarrollo de la comunicación oral y escrita como competencia genérica en la formación profesional de Ingenieros Civiles.

\subsection{Muestra}

Según Tamayo y Tamayo (1999:49), la muestra "es el grupo de individuos que setoma de la población, para estudiar un fenómeno estadístico". En este investigación la muestra seleccionada ha sido no probabilística casual o accidental, debido a que la escogencia de los sujetos que la componen fue arbitraria y fortuita (Arias, 2006). Los estudiantes seleccionados fueron tomados de los listados oficiales de la universidad a los que se tuvo acceso. Como resultado de este proceso se eligieron 20 estudiantes de primer semestre y 20 estudiantes de décimo semestre.

\subsection{Instrumentos}

Proceso metodológico para la aplicación de instrumentos de investigación. La investigación se desarrolló en dos fases:

Primera Fase. Consistió en una aplicación de instrumentos cualitativos divididos en tres momentos:

- Primer momento. Se seleccionaron dos grupos. Uno ellos fue escogido entre estudiantes de primer semestre de Ingeniería Civil, y otro grupo entre los estudiantes de último semestre. El número de unos y otros fue de entre 10 y 25 estudiantes, tal como lo indica el estudio de grupo de discusión.

- Segundo momento. Una vez seleccionados los grupos de estudio se citaron en hora, lugar y día determinados para desarrollar el segundo momento de la investigación, el cual consistió en realizar pinturas enriquecidas o ideografías, antes de lo cual se realizó un trabajo preliminar en la cual se explicaron los objetivos de la investigación y su valor para el fortalecimiento del programa de ingeniería Civil, en su estructura curricular y en el mejoramiento del perfil del egresado.

- Tercer momento. Esta fase estuvo dividida en dos actividades, una individual y otra colectiva. La individual consistió en la elaboración de un escrito con una extensión de una página, que dio cuenta de la explicación de cada pintura enriquecida. Posteriormente, cada subgrupo expuso descriptivamente el significado de los diferentes elementos en el contexto de la totalidad de la pintura, así como la significación general de la misma. Durante esta actividad se pudieron formular diferentes preguntas que buscaban profundizar en la opinión de los diferentes estudiantes y detalles más precisos y descriptivos de su apropiación y desarrollo de competencias genéricas. Uno de los instrumentos que estuvo presente transversalmente en la primera fase fue la observación participante, con la finalidad de obtener una mayor comprensión de lo que estaba ocurriendo de una forma más directa e interactiva. Finalmente, se hizo la explicación por parte de cada grupo y se tomó nota de todo lo que cada miembro del grupo expuso sobre su participación en la pintura enriquecida.

Segunda Fase. En la segunda fase de la investigación se privilegiaron las características, las técnicas e instrumentos cuantitativos. Para ello se empleó un cuestionario cuyo propósito consistió 
en recoger información acerca de las categorías inductivas seleccionadas por los investigadores desde la percepción y opinión de los estudiantes mediante la utilización de una escala Likert.

Durante esta fase también se llevó a cabo la entrevista semi estructurada a una muestra de los docentes de primer y último semestre de Ingeniería Civil. Esta entrevista estuvo programada para una duración promedio de dos horas. En este momento se diligenció de manera organizada una serie de interrogantes sobre las categorías deductivas definidas por los investigadores, que permitiera estimular la producción de opiniones sobre losdiferentesaspectos tratados en las preguntas, buscando que los profesores generaran juicios que pudieran ser generalizados a los grupos.

\section{Resultados y discusión}

A continuación se exponen los resultados de acuerdo con cada uno de los instrumentos utilizados:

\subsection{Análisis del cuestionario}

La figura 1 muestra la percepción de los estudiantes sobre la apropiación de la competencia de comunicación oral y escrita organizados bajo la frecuencia registrada en los distintos valores de la escala. Para ambos semestres, se evidencia una clara tendencia, con alta frecuencia, hacia una posición de acuerdo en que se posee dicha competencia.

Figura 1

Percepciones acerca de la apropiación de la competencia de comunicación oral y escrita

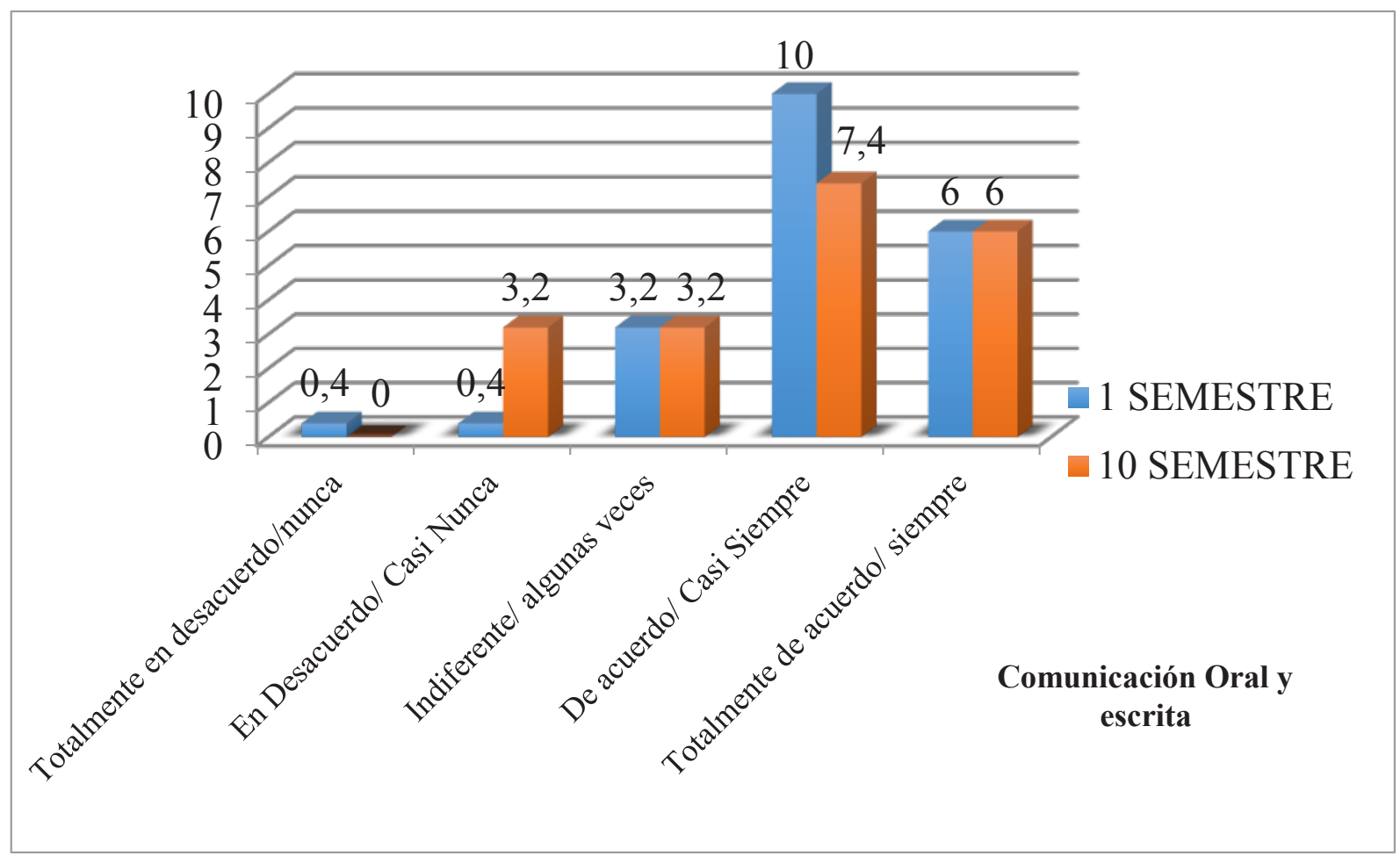

Fuente: Autor, Proceso de investigación. 
Tanto los estudiantes del primer semestre como los del último consideran poseer la habilidad suficiente para comunicarse de forma oral y escrita. Esta afirmación está respaldada por los promedios de 4.0 y 3.8 otorgadas respectivamente por estos semestres, así como la baja dispersión alrededor de estas medias verificadas por la desviación estándar de 0.8 y 1.0 respectivamente. En este sentido es posible establecer que existe una percepción positiva alrededor de la apropiación y desarrollo de la competencia.

Con respecto a la comunicación oral y escrita, los estudiantes de primer y último semestre coinciden en resaltar la importancia de la comunicación en un segundo idioma como primordial para el ejercicio de su profesión. Esta categoría fue valorada con4.0 y 4.05 en su promedio y en su desviación estándar con 0.83 y 0.80 , encontrándose con ello que la percepción de los estudiantes de ambos semestres está concentrada positivamente alrededor de esta categoría inductiva. Por lo tanto, se puede determinar que la muestra es homogénea y permite valorar una percepción positiva de la misma.

De igual manera, los estudiantes de primer semestre consideran poseer la capacidad para escuchar atentamente y la capacidad para comunicar por escrito sus pensamientos, ideas, datos y mensajes. En estos aspectos los estudiantes de primer semestre obtienen un promedio de 4.20 y 4.15 respectivamente con una desviación respectiva de 0.67 y 0.79 .Esta desviación permite inferir una percepción positiva frente a esta categoría inductiva.

Por su parte los estudiantes de décimo semestre consideran poseer la capacidad para escuchar atentamente, que tiene un promedio de 3,95 con desviación de 0,97 , lo cual indica que hay una moderada dispersión alrededor de la media. Esto permite inferir que el $80 \%$ para el primero y el 67\% para el décimo semestre, oscilan alrededor de la media entre de acuerdo/casi siempre y totalmente de acuerdo/siempre. Adicionalmente, la desviación estándar indica la homogeneidad de la muestra alrededor de dichas opiniones. Así, las desviaciones respectivas para primer y décimo semestre fueron
0,8 y 1,0 valores muy cercanos, aceptables en el análisis concluyente con relación a esta categoría.

\subsection{Análisis de la pintura enriquecida}

Con la finalidad de analizar la competencia de comunicación oral se recurrió a la técnica de la pintura enriquecida. Recurriendo a esta herramienta y a los videos, fue posible captar en su contexto, momento a momento, la mayor cantidad de elementos asociados a las diferentes categorías objeto de estudio que fueran posibles.

Figura 2

Comunicación Oral:

Resultados de la observación mediante la pintura enriquecida

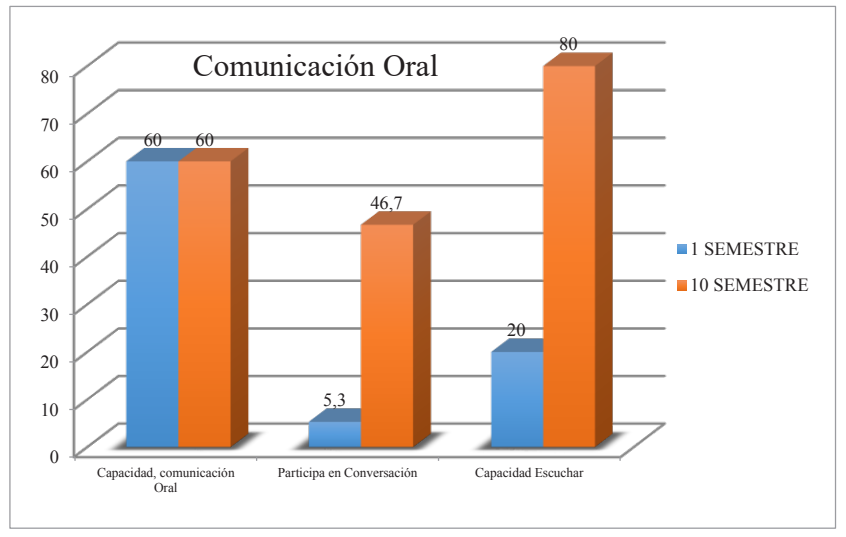

Fuente: Autor, Proceso de investigación.

Para esta categoría deductiva, se tuvieron en cuenta tres categorías inductivas (capacidad de comunicación oral, participación en conversación y capacidad de escuchar), de las cuales se observó de manera general que tanto estudiantes de primero como de último tienen dificultades para hablar en público y expresar con ideas claras lo que plasmaron en sus diferentes trabajos. En efecto, mayormente tomaban la vocería dos integrantes, máximo tres de cada grupo.

Por parte de los investigadores se intentó, a través de diferentes preguntas dirigidas puntualmente a los sujetos que no se atrevían a hablar por iniciativa propia, motivarlos para que expresaran su opinión o sentir frente a lo que se indagaba, pero 
fue difícil lograr una adecuada participación de los mismos. Los resultados muestran que frente a la comunicación oral tienen igual valoración los estudiantes de primero y último semestre y frente a la capacidad de escuchar los de primero estuvieron ajenos a esta, comparados con el último semestre, coherente con lo observado y transcurrido en la actividad.

De acuerdo con el análisis de la pintura enriquecida, frente a la capacidad de comunicación oral del primer semestre en los tres grupos (relaciones mencionadas) organizados para el desarrollo de dicha actividad fue la siguiente: en la relación 1 (empleabilidad) de dos sujetos (2 y 3$)$, frente a tres $(1,2$ y 3$)$ sujetos del último semestre; de la relación 2 (convivencia) tres sujetos $(1,2$ y 3$)$, frente a dos sujetos ( 2 y 3 ) del décimo y finalmente en la relación 3 , un sujeto (3), frente a un sujeto (3) del último semestre, del total de 15 sujetos seleccionados y reorganizados en tres subgrupos, como ya se ha mencionado.

En relación con la participación en la conversación y de manera general, siete sujetos lo evidenciaron igual que los de último semestre, $\mathrm{y}$ por último frente a la capacidad de escuchar los de primer semestre, tres sujetos lo evidencian frente a una buena participación en los estudiantes de último semestre con 12 sujetos. Ello se refleja en el análisis estadístico descriptivo que se expone a continuación:

En cuanto a la comunicación oral, entre el primer y último semestre no hubo variación, pues los estudiantes de último semestre no muestran un incremento significativo. Dicho de otro modo, se mantienen como ingresan a la universidad. En cuanto a la participación en la conversación, tuvieron un incremento en porcentaje del 41,4\%, lo cual implica un desarrollo en esta competencia. Para terminar, frente a la capacidad de escuchar existe un incremento del $60 \%$, de lo cual se deduce que hay una apropiación y desarrollo por parte de los estudiantes de último semestre.

\subsection{Análisis de escritos libres}

El proceso del escrito permite abordar un análisis cualitativo a través del cual se describe la construcción de elaboración de los escritos libres por parte de los estudiantes. Para la evaluación de los escritos se tuvieron en cuenta los siguientes criterios: 1. El escrito es claro en sus ideas y argumentos, está enfocado y bien fundamentado en la pintura enriquecida; 2. Se identifican los propósitos y objetivos de las ideas principales; 3 . La presentación es organizada y coherente con lo desarrollado en la pintura enriquecida; 4. Se incluyen todas las partes o elementos de la pintura enriquecida de una manera directa y apropiada; 5 . Demuestran dominio del tema expuesto al explicar el contenido del mismo; 6 . Se identifica la originalidad del documento; 7. El texto se construye teniendo en cuenta reglas ortográficas y gramaticales; 8 . Se utiliza un vocabulario preciso, correcto y apropiado; 9. Contiene oraciones y párrafos bien construidos que facilitan la lectura y comprensión del escrito y 10. Calidad de la presentación.

Con la plantilla de control y los aspectos anteriormente mencionados se buscó evidenciar e identificar si los estudiantes de primer y último semestre de la carrera de Ingeniería Civil se han apropiado y desarrollado la competencia genérica concerniente a la comunicación escrita. Esta actividad se desarrolló después de que los estudiantes de primer y último semestre realizaran su exposición de la pintura enriquecida frente a los docentes investigadores. Para llevar a cabo esta actividad se entregó a cada uno de los estudiantes pertenecientes a los grupos de empleabilidad, ser humano y convivencia, una hoja donde deberían plasmar las ideas mencionadas en la pintura enriquecida, con el fin de analizar la coherencia de la misma y su escrito. Para ello se les dio un tiempo de 15 minutos.

La información sobre el escrito fue consignada en la plantilla de control de acuerdo con los criterios personales de los investigadores siendo estos categorizados en la misma a partir de respuestas 
como:1) bueno; 2) aceptable y 3) deficiente. ambos grupos se refleja en la figura 5. La diferencia Los resultados en cada uno de los indicadores mencionados para el primer semestre se muestran en la figura 3 . Los del décimo semestre aparecen en la figura 4. Una comparación de los indicadores entre

Figura 3

Escrito libre primer semestre

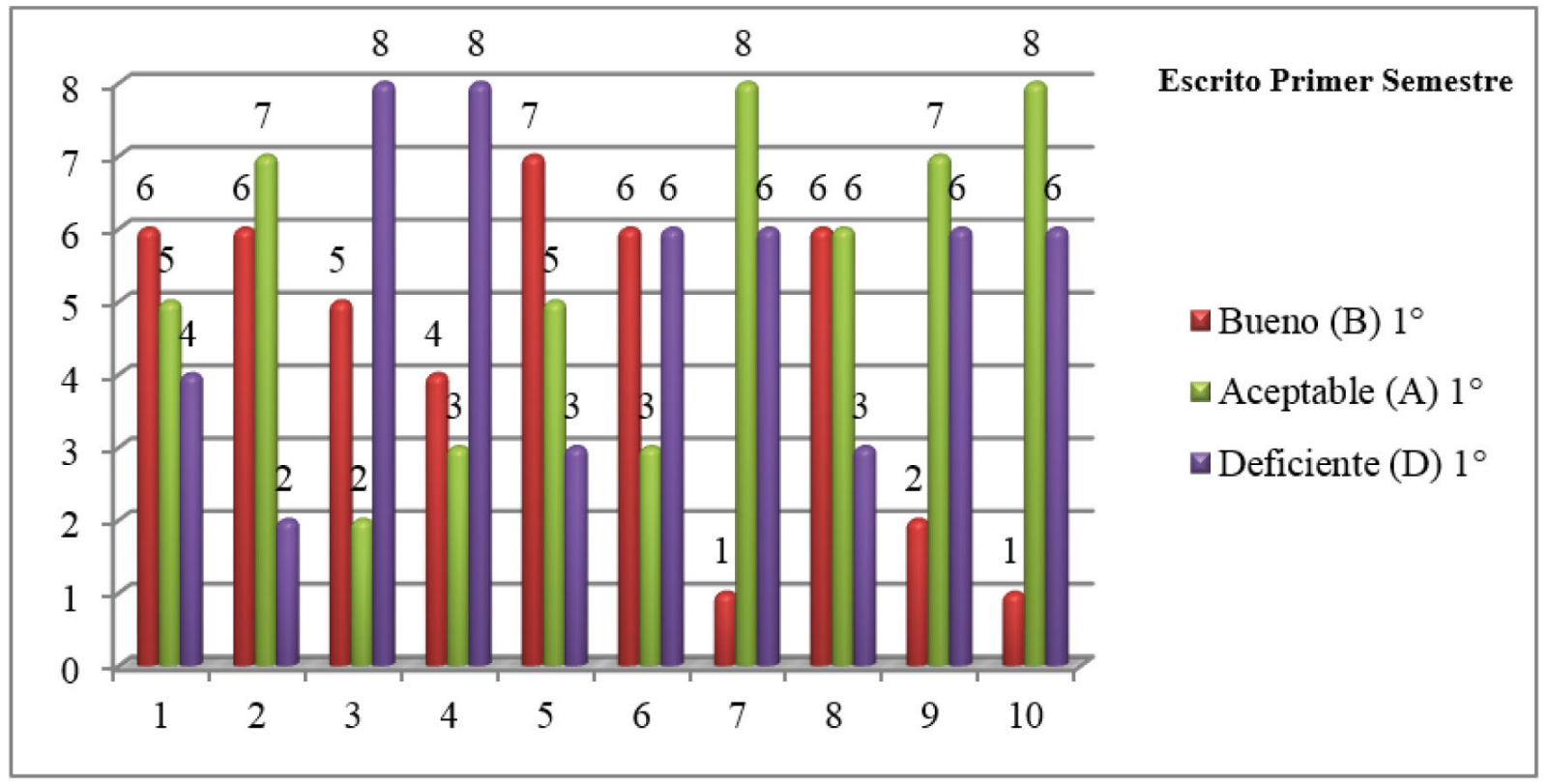

Fuente: Autor, Proceso de investigación.

Figura 4

Escrito libre décimo semestre

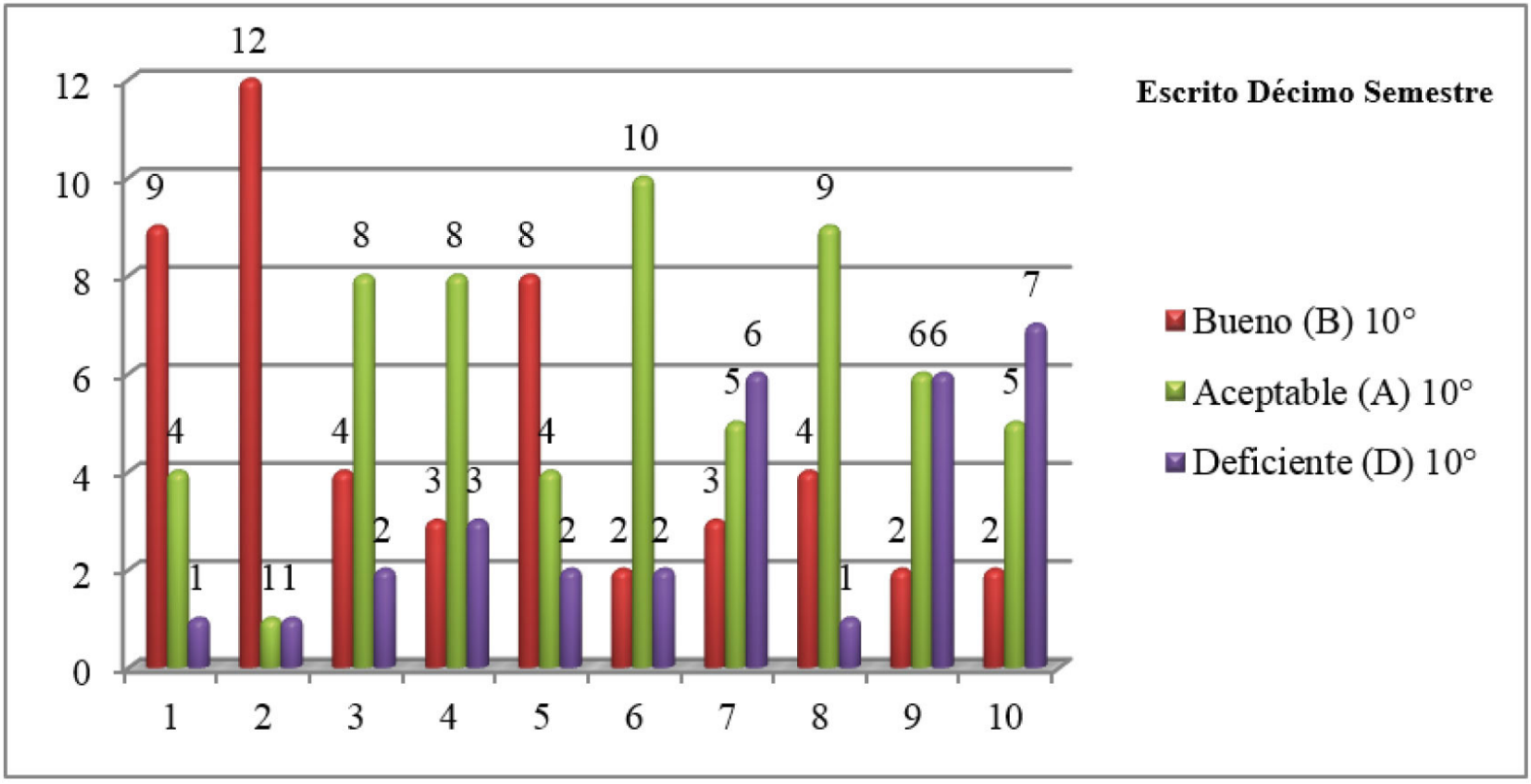

Fuente: Autor, Proceso de investigación. 
Figura 5

Comparativo escritos libres primer y décimo semestre

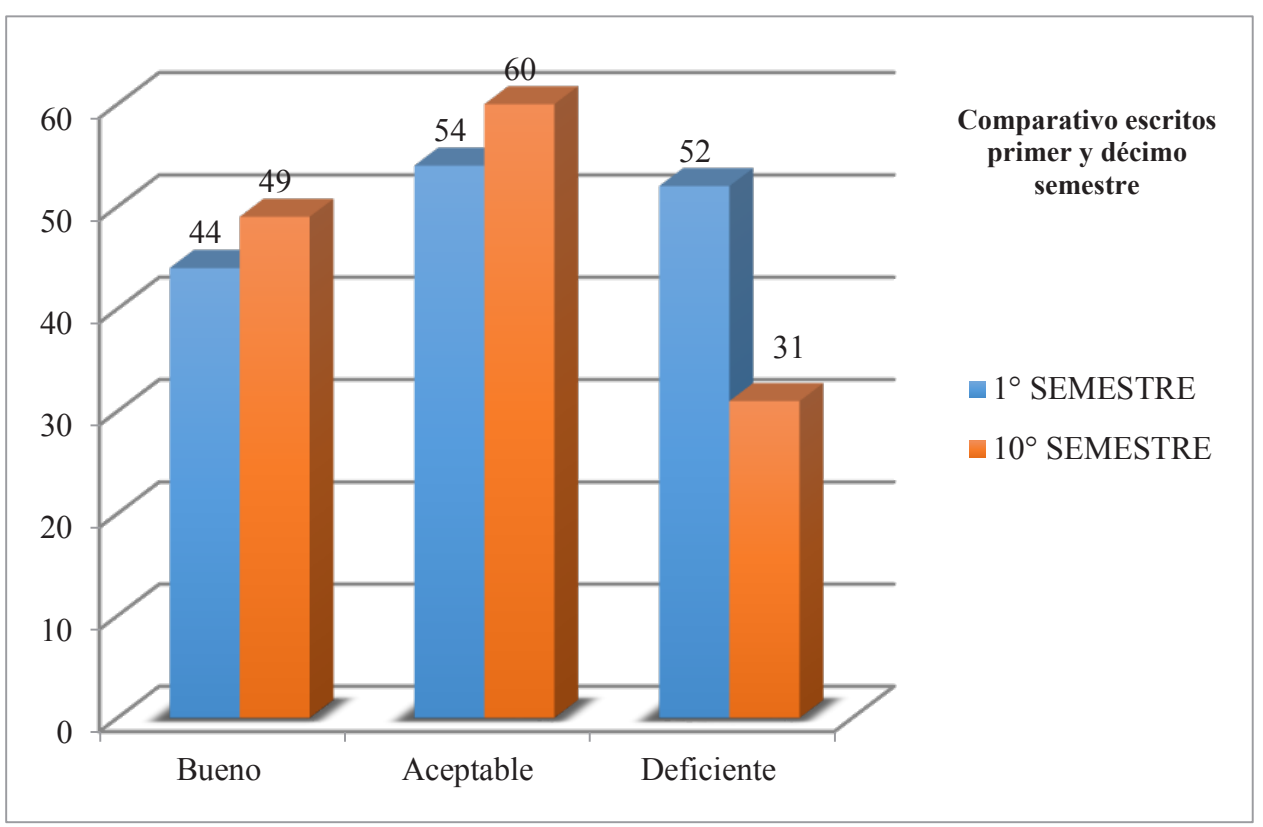

Fuente: Autor, Proceso de investigación.

Figura 6

Resultados comparativos de la competencia comunicación oral y escrita para ambos grupos

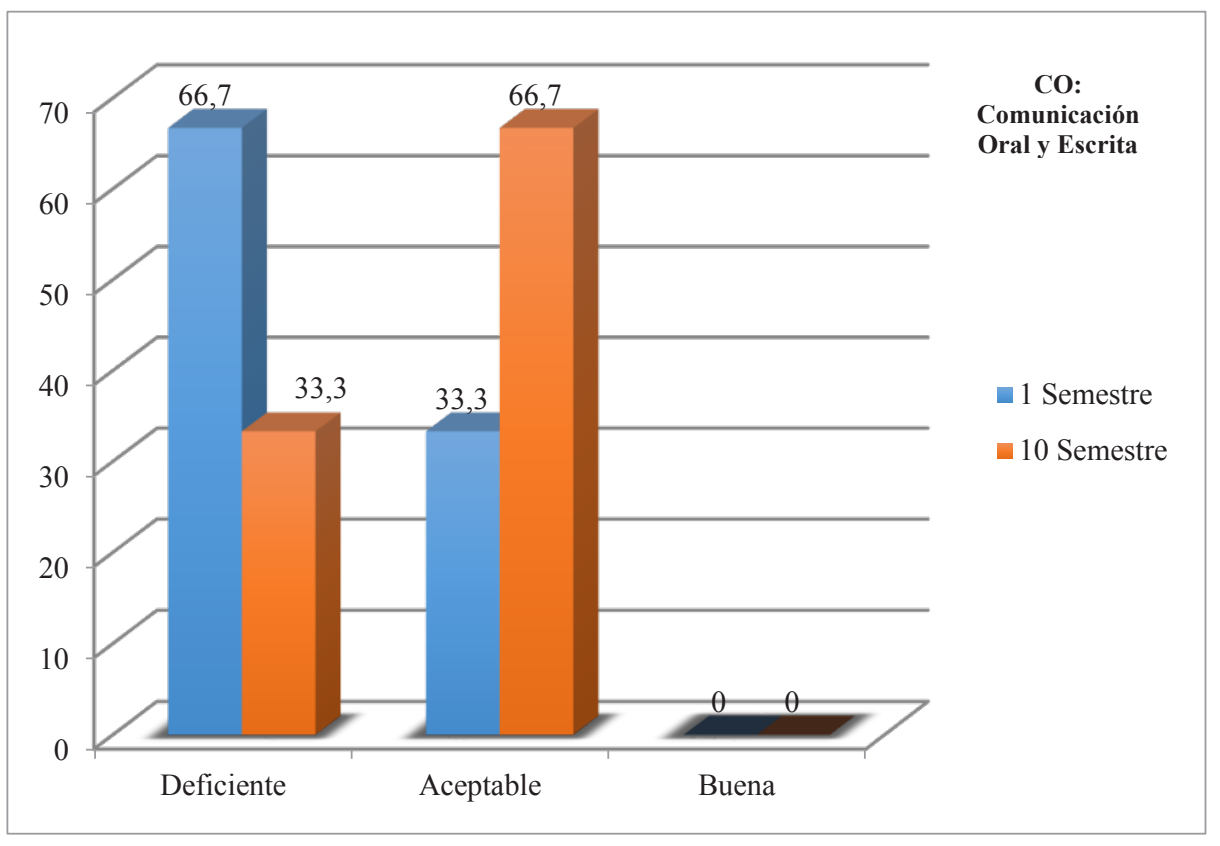

Fuente: Autor, Proceso de investigación. 
Siendo la comunicación oral y escrita un aspecto de vital importancia en el éxito profesional, vale la pena realizar un análisis que tenga en cuenta los criterios evaluativos establecidos inicialmente, lo cual permitió revelar las fortalezas y deficiencias que tienen los estudiantes.

En este sentido se concluyó que, en general, los estudiantes de primer semestre se encuentran ubicados en criterios aceptables con relación a la matriz de control diseñada. Se pudo observar en la mayoría de los escritos que no son claros, las ideas y argumentos de la presentación adolecen de profundidad, no están enfocados y falta fundamentación desde la pintura enriquecida, pues en la gran mayoría de los textos, no se observa una clara identificación en el propósito y en las ideas principales que se describen, así como la coherencia de las mismas y la secuencia de presentación. Se pueden observar algunas dificultades encontradas en la coherencia, lógica y originalidad con relación a lo plasmado en la pintura enriquecida. Algunos de ellos presentan una descripción sin sentido secuencial y temático. Atendiendo a las normas gramaticales y de ortografía,son evidentes errores frecuentes. Así mismo quedan patentes las deficiencias en la utilización adecuada del vocabulario en cuanto al significado preciso para expresar una idea.Como muestra de lo anterior se encuentran oraciones y párrafos mal construidos, que dificultan la lectura y comprensión del escrito.

Aunque es posible evidenciar en los resultados de estudiantes que presentan fortalezas en algunos de los aspectos o criterios de evaluación establecidos en la matriz de control, hay que decir que estos no se corresponden con el grueso de la muestra, que por el contrario se encuentran ubicados en la aceptabilidad de los mismos. También se puede registrar que existen casos mucho más graves entre los estudiantes, que además de los factores antes mencionados, poseen una grafía bastante deficiente. Así, se registran dificultades que obstaculizan el rendimiento académico y profesional del estudiante.

Por otra parte, entre los estudiantes de último semestre se observa que en algunos de sus escritos identificaron el propósito de la actividad de la pintura enriquecida, expresando de una manera clara los objetivos e ideas principales. De igual manera, los docentes investigadores pudieron determinar que los escritos describían las partes y elementos constitutivos y realizados en la pintura por parte de cada uno de los grupos. Además, los estudiantes demostraron poder explicarla medianamente. También se demostró la originalidad de algunos textos en lo que respecta al estilo y a la estética del desarrollo de las ideas.

En cuanto a la presentación del escrito, se observa que los párrafos no son muy ordenados, ni coherentes, y su constitución impide que la lectura sea amena y ágil. Además, demuestran un regular manejo de la ortografía y de las reglas gramaticales.

\section{Conclusiones}

Para el análisis de la competencia objeto de investigación se tomaron por separado tres aspectos: el oral, el escrito y el de la comunicación en un segundo idioma. Cada uno de estos aspectos fue analizado luego de la aplicación de los diferentes instrumentos de recolección de información.

El análisis de la información obtenida mediante el cuestionario permite concluir que tanto los estudiantes del primer semestre como los de último consideran poseer la habilidad para comunicarse de forma oral y escrita. En este sentido es posible establecer que existe una percepción positiva alrededor de la apropiación y desarrollo de la competencia. Sin embargo, y pese a esta percepción en el desarrollo y ejecución de la pintura enriquecida, se vislumbraron falencias significativas a la hora de expresar oralmente y por escrito las ideas presentadas gráficamente.

Asimismo, es de resaltar que fue mucho más fácil, ágil y fluido el lenguaje pictórico que el expresado por otros medios, en los que se observó un grado de creatividad menor que en el ejercicio de la pintura. En esta dirección se pudieron extraer ideas claras sobre las competencias que consideran importantes en la consolidación de los atributos, capacidades o habilidades como categorías inductivas. 
Cuando se comparan los resultados de la pintura enriquecida frente a la capacidad de comunicación oral, el primer semestre, con relación al último, resultó significativamente inferior. En efecto, los estudiantes de décimo semestre muestran una mayor participación de sus integrantes. Sin embargo, frente a la capacidad de escuchar, los estudiantes de primer semestre muestran una mejor disposición que los de último semestre.

No obstante los resultados manifiestos anteriormente, en la exposición de la pintura enriquecida los estudiantes de primer semestre conceden una significativa importancia a la comunicación oral. Así lo permiten ver las pinturas elaboradas por los diferentes grupos que abordaron diferentes relaciones entre competencias genéricas y empleabilidad, ser humano y convivencia. Por otra parte, aunque no lo privilegian como motivo de algún aspecto de las pinturas, los estudiantes de décimo semestre mostraron mayor seguridad y fluidez verbal en su exposición. En esta dirección es importante mencionar que en el momento de la exposición de la pintura enriquecida se encontraron muchos estudiantes asilados, tímidos e inseguros que se privaron de la posibilidad de expresar sus opiniones. La causa de ese comportamiento habría que buscarla sobre todo en limitaciones psicológicas como el exceso de timidez o la falta total de confianza en sí mismos (Villa y Poblete, 2007).

En cuanto a las opiniones emanadas de la entrevista semi estructurada se pudo establecer que los estudiantes de primer semestre se comunican oralmente mejor de lo que escriben y que la comunicación en un segundo idioma es deficiente. El léxico que fundamenta sus ideas es incipiente, y pese a las dificultades que se enfrentan en la educación secundaria es posible observar algunos estudiantes con esta competencia desarrollada. Las barreras en la comunicación son permanentes. En muchas ocasiones pensamos que nuestras palabras expresan lo que nuestras ideas y sentimientos manifiestan, que nuestras palabras dicen lo que sentimos y pensamos y que los oyentes lo han comprendido, pero la realidad es otra. Ella nos demuestra que, tanto en nuestra vida personal como en nuestras relaciones profesionales, hay una gran abismo entre lo que pensábamos manifestar y lo que ha comprendido quien nos escucha (Villa y Poblete, 2007 ).

Por otra parte, la opinión con respecto a los estudiantes de décimo semestre es más preocupante, debido a que los profesores manifiestan queno existen estrategias efectivas para mejorar la comunicación en un segundo idioma y que la comunicación oral, aunque mejor, es deficiente, al igual que la escrita. Esto lleva a pensar que las estrategias diseñadas por la universidad son ineficientes con relación a las políticas institucionales para mejorar en estos aspectos.

En cuanto al escrito libre presentado como parte del ejercicio de elaboración de la pintura enriquecida, la mayoría de los escritos de los estudiantes de primer semestre no son claros, las ideas y argumentos de la presentación adolecen de profundidad y hay poca coherencia e hilvanación de ideas desde la pintura enriquecida. En la gran mayoría de los textos no se observa una clara identificación en el propósito que se describe, así como la secuencia de presentación. Se puede observar algunas dificultades encontradas en la coherencia, lógica y originalidad con relación a lo plasmado en la pintura enriquecida. Algunos de ellos presentan una descripción sin sentido secuencial y temático. Atendiendo las normas gramaticales y de ortografía es evidente observar errores frecuentes en la utilización de las reglas. Así mismo es posible observar deficiencias en la utilización adecuada del vocabulario así como con el significado preciso que se quiso establecer para expresar una idea. Como reflejo de lo anterior se encuentran oraciones y párrafos mal construidos que dificultan la lectura y comprensión del escrito.

Por otra parte, entre los estudiantes de último semestre se encuentra que algunos no identificaron en sus escritos el propósito de la actividad de la pintura enriquecida, quedando desdibujados los objetivos e ideas principales. De igual manera, los docentes investigadores pudieron determinar que los escritos describían las partes y elementos constitutivos y 
realizados en la pintura enriquecida por parte de cada uno de los grupos. Además, los estudiantes demostraron poder explicar medianamente la pintura enriquecida con originalidad de estilo.

En cuanto a la presentación del escrito, se observa que los párrafos no son ordenados ni coherentes, y su constitución impide que la lectura sea amena y ágil. Además, demuestran un conocimiento deficitario de la ortografía y de las reglas gramaticales.

Como corolario, es preciso recordar que la capacidad de transmitir ideas, información y sentimientos a través de la escritura no es innata. Se desarrolla con la práctica, siguiendo instrucciones o imitando los modelos a los que tenemos acceso a través de la lectura (Villa y Poblete, 2007). Corresponde a todos los niveles educativos, incluida la Universidad, crear condiciones de aprendizaje apropiadas para potenciar la comunicación verbal y en un segundo idioma.

\section{Referencias}

Arias, F. (2006). Mitos y errores en la elaboración de tesis. Caracas: Episteme.

Borrero, L. (2008). La competencia oral y escrita en la educación superior. Disponible en 189357 archivo_pdf_comunicacion.pdf

Camargo, M., Vergara, M., Calvo, G., Londoño, S., Franco, M. C., Zapata, F. y Garavito, C. (2004). Las necesidades de formación permanente del docente. Educación y educadores, 7, 79-112.

Cano, E. (2008). La evaluación por competencias en la educación superior. Profesorado: revista de currículum y formación del profesorado, 12(3).

Díaz, Á. (1999). Aproximación al texto escrito. Medellín: Universidad de Antioquia.

Fraca, L. 2003. Pedagogía integradora en el aula: teoría, práctica y evaluación de las estrategias de adquisición de competencias cognitivas y lingüísticas para el empleo efectivo de la lengua materna oral y escrita. Caracas: CEC

Galvis, R. V. (2007). De un perfil docente tradicional a un perfil docente basado en competencias.
Acción pedagógica, 16(1), 48-57.

Morales, O. (2002). ¿Cómo contribuir con el desarrollo de las competencias de los estudiantes universitarios como productores de textos? Educere, 5(16): 385-389.

Ríos, Y.(2008). El discurso académico oral en el marco de la nueva retórica. Revista iberoamericana de educación, 50, 1-10.

Romero, N. (2005). ¿Y qué son las competencias? ¿Quién las construye? ¿Por qué competencias? Revista Educar, 9-18.

Tamayo, M. y Tamayo, R. (1999). El proyecto de investigación. Bogotá: ICFES .

Villa, A. y Poblete, M. (2007). Aprendizaje basado en competencias: Una propuesta para la evaluación de las competencias genéricas. Bilbao: Mensajero.

Zabalza, M. A. (2005). Competencias docentes. Cali: Pontificia Universidad Javeriana. 